\title{
PENGARUH BUDAYA ORGANISASI TERHADAP KINERJA PEGAWAI PADA SEKRETARIAT DPRD PROVINSI LAMPUNG
}

\author{
Fahrizi $^{(1)}$, Gita Panlela ${ }^{(2)}$ \\ Fakultas Ekonomi Universitas Sang Bumi Ruwa Jurai \\ fahrizi@fe.saburai.ac.id,gita_panlela11@gmail.com
}

\begin{abstract}
Abstrak. Budaya organisasi adalah seperangkat nilai yang mengendalikan interaksi antara suatu individu dalam organisasi dengan individu lain dalam organisasi, atau organisasi lain sebagai pemasok, dan anggota masyarakat yang dilayani. Budaya organisasi dibentuk oleh para individu dalam organisasi, etika organisasi yang dianut, hak kepegawaian yang diberikan kepada tiap pegawai dan juga jenis struktur organisasi itu sendiri. Permasalahan dalam penelitian ini adalah Apakah budaya organisasi berpengaruh terhadap kinerja pegawai pada Sekretariat DPRD Provinsi Lampung. Tujuan dari penelitian ini adalah untuk mengetahui pengaruh antara budaya organisasi terhadap kinerja pegawai pada Sekretariat DPRD Provinsi Lampung. Penelitian ini menggunakan metode analisis kualitatif dan kuantitatif. Pengumpulan data penelitian menggunakan teknik populasi dari seluruh pegawai pada Sekretariat DPRD Provinsi Lampung berjumlah 49 orang. bahwa persentase persentase sumbangan perubahan variabel independen budaya organisasi (X) terhadap variabel dependen kinerja (Y) sebesar 97,8\% dan sisanya dipengaruhi faktor lain. Uji hipotesis parsial melalui uji t test diperoleh nilai t hitung budaya organisasi terhadap kinerja sebesar 45,893 dan thitung = 45,893 > ttabel 1,678 maka Ho ditolak dan Ha diterima. Dengan demikian berarti bahwa ada pengaruh budaya organisasi terhadap kinerja pegawai pada Sekretariat DPRD Provinsi Lampung.
\end{abstract}

Kata Kunci : Budaya Organisasi, Kinerja,Pegawai.

\section{PENDAHULUAN}

Pada masa perkembangan teknologi dewasa ini, mempunyai peranan yang sangat penting karena kinerja dari seorang pegawai sebagai aparatur sipil negara akan mempengaruhi faktor yang lain. Menyadari bahwa manusia adalah faktor penentu yang sangat penting dan menjadi pusat perhatian dari setiap kegiatan operasionalnya maka setiap organisasi dituntut mengelola sumber daya manusia yang ada agar tujuan yang diharapkan dapat tercapai. Pada dasarnya, kemampuan berfikir dan kemampuan mental yang handal dalam bertindak merupakan potensi yang telah ada pada manusia.

Organisasi merupakan kesatuan sosial yang dikoordinasikan secara sadar dengan sebuah batasan yang relatif dapat diidentifikasikan, bekerja secara terus menerus untuk mencapai tujuan (Robbins, 2006 : 127). Akibat terjadinya interaksi dengan karakteristik masing-masing serta banyak kepentingan yang membentuk gaya hidup, pola perilaku, dan etika kerja, yang kesemuanya akan mencirikan kondisi suatu organisasi. Sehingga setiap individu dalam organisasi tidak lepas dari hakekat nilainilai budaya yang dianutnya, yang pada akhirnya akan bersinergi dengan perangkat organisasi, teknologi, system, strategi dan gaya hidup kepemimpinan. Sehingga pola interaksi sumber daya manusia dalam berorganisasi harus diseimbangkan dan diselaraskan agar organisasi dapat tetap eksis.

Budaya organisasi adalah seperangkat nilai yang mengendalikan interaksi antara suatu individu dalam 
organisasi dengan individu lain dalam organisasi, atau organisasi lain sebagai pemasok, dan anggota masyarakat yang dilayani. Budaya organisasi dibentuk oleh para individu dalam organisasi, etika organisasi yang dianut, hak kepegawaian yang diberikan kepada tiap pegawai dan juga jenis struktur organisasi itu sendiri. Budaya organisasi juga membentuk dan mengendalika perilaku dalam keorganisasiaan. Budaya organisasi mempengaruhi cara individu merespon dan menafsirkan segala situasi dan permasalahan yang dihadapi.

Budaya organisasi merupakan kumpulan nilai yang dianut dalam organisasi dan mendasari bagaimana mengelola organisasi tersebut. Nilai-nilai itu merupakan keyakinan yang dipegang teguh dan kadang-kadang tidak terungkap.

Budaya organisasi berpengaruh pada perilaku anggota atau individu serta kelompok di dalam suatu organisasi dan perilaku tersebut berpengaruh pada pencapaian prestasi sehingga secara bersama-sama akan berpengaruh pada efektif atau tidaknya pencapaian organisasi (Pabundu, 2006).

Menurut (Simanjuntak, 2011 : 1) kinerja adalah tingkat pencapaian hasil atas pelaksanaan tugas tertentu. Kinerja organisasi adalah tingkat pencapaian hasil dalam rangka mewujudkan tujuan organisasi. Manajemen kinerja adalah keseluruhan kegiatan yang dilakukan untuk meningkatkan kinerja organisasi, termasuk kinerja masing-masing individu dan kelompok kerja di organisasi tersebut. Kinerja individu, kinerja kelompok dan kinerja organisasi, dipengaruhi oleh banyak faktor intern dan ekstern organisasi

Tabel Daftar Kehadiran Sekretariat DPRD Provinsi Lampung

\begin{tabular}{|l|l|}
\hline BULAN & $\begin{array}{l}\text { PERSENTASE } \\
(\mathbf{\%})\end{array}$ \\
\hline September & 80,24 \\
\hline Oktober & 79,25 \\
\hline
\end{tabular}

\begin{tabular}{l|l|}
\hline November & 76,89 \\
\hline Desember & 80,45 \\
\hline Januari & 82,68 \\
\hline Februari & 78,43 \\
\hline Maret & 87,56 \\
\hline April & 76,23 \\
\hline Mei & 78,90 \\
\hline Juni & 82,63 \\
\hline Juli & 77,65 \\
\hline Rata-Rata & $\mathbf{8 0 . 0 8}$ \\
Sumber : Sekretariat DPRD Provinsi Lampung \\
Tahun 2017
\end{tabular}

Berdasarkan tabel kehadiran diatas, dapat terlihat bahwa masih belum sepenuhnya pegawai dapat hadir ke kantor, dan juga dapat terlihat adanya fluktuasi. Ini diperlukan adanya tindakan dari pimpinan agar dapat meningkatkan semangat kerja pegawainya, dengan demikian maka kinerja pegawai pun akan meningkat.

\section{Sekretariat DPRD Provinsi}

Lampung sebagai pusat pemerintahan daerah dalam melakukan pembangunan daerah tentunya harus didukung dengan kemampuan Aparatur Negeri Sipil yang berkualitas. Sekretariat DPRD Provinsi Lampung memiliki 196 pegawai. Berdasarkan observasi yang telah dilakukan di Sekretariat DPRD Provinsi Lampung terdapat indikasi masih rendahnya budaya organisasi dari para Aparatur Negeri Sipil yang berada di instansi tersebut serta dari aktivitas kegiatan sehari hari seperti kurangnya kegiatan organisasi yang bisa mewujudkan hubungan yang baik antara sesama pegawai dan pimpinan maupun antar sesama pegawai. Dalam kaitannya dengan kinerja pegawai, itu akan membuat semangat kerja pegawai yang dapat mengakibatkan menurunnya kinerja pegawai, hal tersebut seharusnya segera dibenahi agar para pimpinan dan bawahan pegawai negeri sipil di Sekretariat DPRD Provinsi Lampung dapat memberikan pelayanan yang prima kepada masyarakat secara lebih profesional.

Berdasarkan uraian tersebut diatas, maka peneliti tertarik untuk mengadakan 
penelitian dengan judul "Pengaruh Budaya Organisasi terhadap Kinerja
Pegawai pada Sekretariat
Provinsi Lampung."

\section{KAJIAN TEORI}

\section{Pengertian Budaya Organisasi}

Menurut (Robbins dan Judge, 2008:

256) Ide untuk memandang organisasi sebagai kultur - dimana terdapat sebuah sistem makna yang dimiliki bersama oleh para anggotanya - merupakan sebuah fenomena yang relatif baru. Sedangkan menurut (Laudon dan Laudon, 2012 : 100) Seluruh organisasi memiliki asumsi dasar, yang tak dapat dibantah, dan tidak dapat dipertanyakan (oleh anggotanya) yang menjelaskan tujuan dan produk organisasi tersebut. Budaya organisasi meliputi seperangkat asumsi ini mengenai produk apa yang harus diproduksi organisasi, bagaimana organisasi memproduksinya, dimana dan untuk siapa.

Dengan demikian, sebuah organisasi yang telah mempunyai sistem makna yang dimiliki bersama oleh para anggotanya, mempunyai asumsi dasar yang menjelaskan tujuan organisasi tersebut, dapat dikatakan bahwa organisasi tersebut telah memiliki budaya organisasi. Budaya organisasi terdiri dari 2 kata yaitu budaya dan organisasi.

Menurut (Rivai dan Mulyadi, 2012 : 373) pengertian budaya menurut definisi, budaya itu sukar dipahami, tidak berwujud, implisit dan dianggap sudah semestinya atau baku. Definisi lain menyebutkan budaya adalah sejumlah pemahaman penting seperti norma, nilai, sikap, dan keyakinan yang dimiliki bersama oleh anggota organisasi. Menurut (Laudon dan Laudon, 2012 : 97) bahwa organisasi adalah struktur formal yang stabil dan formal yang mengambil sumber daya dari lingkungan dan memprosesnya untuk menciptakan output. Dari penggabungan 2 kata yaitu budaya dan organisasi, maka menjadi budaya organisasi yang memiliki definisi atau arti tersendiri.

Menurut (Robbins dan Judge, 2008 :

256) bahwa Kultur organisasi (organizational culture) mengacu pada sebuah sistem makna bersama yang dianut oleh para anggota yang membedakan organisasi tersebut dengan organisasi lainnya. Menurut (Rivai dan Mulyadi, 2012 : 374), menyatakan bahwa budaya organisasi adalah suatu kerangka kerja yang menjadi pedoman tingkah laku sehari-hari dan membuat keputusan untuk karyawan dan mengarahkan tindakan mereka untuk mencapai tujuan organisasi.

Laudon dan Laudon, 2012 : 100) menyatakan bahwa budaya organisasi adalah kekuatan pengikat yang kuat yang menghambat konflik politik dan mendorong pemahaman yang sama, perjanjian pada prosedur, dan praktik umum. Menurut (Tintami et al. 2012 : 3) bahwa budaya organisasi adalah filosofi dasar organisasi yang memuat keyakinan, norma-norma, dan nilai-nilai bersama yang menjadi karekteristik inti tentang bagaimana melakukan sesuatu dalam organisasi. Keyakinan, norma-norma, dan nilai-nilai tersebut menjadi pegangan semua sumber daya manusia dalam organisasi dalam melaksanakan kinerjanya (Wibowo, 2011 : 19).

Dari beberapa pendapat tersebut diatas, maka dapat ditarik sebuah kesimpulan bahwa "budaya organisasi adalah suatu nilai-nilai yang diyakini (belief) dan merupakan sistem dalam suatu organisasi yang mendukung dalam pelaksanaan kegiatan dalam berorganisasi yang mempunyai ciri-ciri tertentu untuk mencapai tujuan yang telah disepakati bersama". 


\section{Faktor-Faktor yang Mempengaruhi Kinerja}

Kinerja seorang pegawai dapat dipengaruhi berbagai faktor, baik faktor eksternal maupun internal dari pegawai tersebut. Simamora dalam (Mangkunegara, 2012 : 14) mengatakan bahwa kinerja pada umum nya dipengaruhi oleh tiga faktor, yaitu:

1. Faktor individual yang terdiri dari:
a. Kemampuan dan keahlian
b. Latar belakang
c. Demografi

2. Faktor psikologis yang terdiri dari:
a. Persepsi
b. Kelakuan (Attitude)
c. Sifat (Personality)
d. Pembelajaran
e. Motivasi

3. Faktor organisasi yang terdiri dari:
a. Sumber daya
b. Kepemimpinan
c. Penghargaan
d. Struktur
e. Job Design

\section{METODE PENELITIAN}

\section{Objek Penelitian}

Objek penelitian ini adalah Sekretariat DPRD Provinsi Lampung di jalan Wolter Mongonsidi No. 69 Teluk Betung Bandar Lampung. Penelitian dilaksanakan dari bulan April 2017 sampai dengan bulan Juli 2017.

\section{Metode dan Teknik Pengumpulan Data}

Dalam penelitian ini metode pengumpulan data adalah :

a. Data primer merupakan data yang diperoleh langsung tanpa pengrantara orang atau lembaga lain sebagai pihak ketiga, data primer diperoleh dengan wawancara melalui responden.

b. Data sekunder diperoleh dengan cara melakukan studi dokumenter, yaitu mengumpulkan data- data dan mempelajari brosur - brosur serta dokumen perusahaan yang berhubungan dengan permasalahan.

\section{Sampel dan Populasi}

Teknik sampel yang digunakan dalam penelitian ini adalah dengan menggunakan teknik Random Sampling, yaitu menentukan jumlah sampel secara acak, dengan jumlah populasi 196 orang. Besarnya jumlah sampel adalah dengan mengikuti pendapat (Zainal Mustafa, 2004 : 6), yaitu semakin besar sampel yang diambil semakin tinggi tingkat representatifnya terhadap populasi.

Menurut pendapat (Suharsimi Arikunto, 2010) bahwa jika anggota populasi lebih besar dari 100 maka dapat dilakukan metode sampling dengan mengambil sampel sebesar $10 \mathrm{sd} 25 \%$ dari anggota populasi. Dengan dasar tersebut, $25 \% \times 196=49$ orang responden sebagai sampel, mewakili keseluruhan pegawai yang berjumlah 196 orang.

\section{Metode Analisis Data}

Untuk pengolahan data dalam bentuk tabulasi hasil jawaban responden kemudian dilakukan analisis data melalui metode analisis secara kualitatif dan analisa kuantitatif.

Analisis kuantitatif yaitu menganalisis dengan menggunakan angka - angka yang dihimpun dari data perusahaan yang berkaitan dengan permasalahan yang dihadapi instansi. Dalam analisis kuantitatif ini penulis menggunakan perhitungan dengan SPSS for windows version 20.0 dengan pendekatan rumus Regresi linier 
Sederhana, dimana formulanya sebagai berikut :

$$
Y=a+b X+e
$$

Keterangan:

$$
\begin{aligned}
& \mathrm{Y}=\text { Kepuasan kerja } \\
& \mathrm{a}=\text { Konstanta } \\
& \mathrm{b}=\text { Koefisien regresi } \mathrm{X} \\
& \mathrm{X}=\text { Kompensasi } \\
& \mathrm{e}=\text { Faktor kesalahan }
\end{aligned}
$$

(Sugiyono, 2005)

Untuk uji validitas adalah suatu ukuran yang menunjukkan tingkat validitas atau kesahihan suatu instrumen, sebuah instrumen dikatakan valid apabila mampu mengukur apa yang seharusnya diukur dengan menggunakan rumus Korelasi Product Moment.

$$
r_{x y}=\frac{n \cdot \sum X Y-\left(\sum X\right)\left(\sum Y\right)}{\sqrt{\left\{n \cdot \sum X^{2}-\left(\sum X\right)^{2}\right\}\left\{n \cdot \sum Y^{2}-\left(\sum Y^{2}\right\}\right)}}
$$

Dimana:

$r_{x y}=$ Nilai antara $\mathrm{X}$ dan $\mathrm{Y}$

$\mathrm{X}=$ Variabel bebas. (nilai skore)

$\mathrm{Y}=$ Variabel terikat (nilai skore)

$\mathrm{n} \quad=$ Jumlah sampel

(Sudjana, 1999:38)

Pengujian validitas dilakukan dengan menggunakan alat bantu program statistik, dengan kriteria sebagai berikut :

a. Jika $r_{\text {hitung }}$ positif dan $r_{\text {hitung }}>r_{\text {tabel }}$ maka butir pertanyaan tersebut valid.

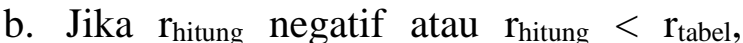
maka butir pertanyaan tersebut tidak valid.

c. $\mathrm{r}$ hitung dapat dilihat pada kolom Corrected Item Total corelation.

Untuk mengetahui nilai distribusi nilai $r_{\text {tabel }}$ nilai Signifikansi 5\% atau 0,05

Uji reliabilitas, untuk melihat reliabilitas masing-masing instrumen yang digunakan, maka peneliti menggunakan koefisien cronbach alpha. Suatu instrumen dikatakan reliable jika memiliki nilai cronbach alpha lebih besar dari 0,6 (Ghozali 2009).

$$
r_{11}=\left[\frac{k}{(k-1)}\right]\left[1-\frac{\sum \sigma_{b}{ }^{2}}{\sigma_{t}^{2}}\right]
$$

Dimana :

$\mathrm{r}_{11}=$ reliabilitas instrumen

$\mathrm{k} \quad=$ banyaknya butir pernyataan

$\sum{\sigma_{b}}^{2}=$ jumlah varians butir

$\sigma_{t}{ }^{2}=$ varians total

(Sugiyono, $2008: 219$ )

Untuk uji statistik $\mathrm{t}$ disebut juga sebagai uji signifikasi individual dengan rumus sebagai berikut:

$$
t=\frac{r \sqrt{n-2}}{\sqrt{1-\mathrm{r}^{2}}}
$$

Dimana :

$\mathrm{t}=$ Penguji koefisien korelasi

$\mathrm{r}=$ Korelasi

$\mathrm{n}=$ Jumlah sampel

(Sudjana, $1999:$ 50)

Hasil pengujian signifikansi dapat juga dilihat dari besarnya nilai signifikansi yang diperoleh yaitu:

1. Jika nilai signifikansi $<0,05$ maka Ho ditolak dan Ha diterima.

2. Jika nilai signifikansi $>0,05$ maka Ho diterima dan Ha ditolak.

Yang dimaksud dengan Hipotesis nol (Ho) dan Hipotesis alternatif (Ha) adalah:

Ho $: r=0=$ Berarti tidak ada pengaruh antara budaya organisasi terhadap kinerja pegawai pada Sekretariat DPRD Provinsi Lampung.

$H a: r \neq 0=$ Berarti ada pengaruh antara budaya organisasi terhadap kinerja pegawai pada 
Sekretariat

DPRD

Provinsi Lampung.

\section{HASIL DAN PEMBAHASAN}

\section{Analisis Kualitatif}

Berikut data distribusi hasil tanggapan responden variabel Budaya Organisasi (X) dan Kinerja (Y) secara keseluruhan.

Tabel Distribusi Data Budaya Organisasi (X) secara keseluruhan

\begin{tabular}{|c|c|c|c|c|}
\hline No & Skor & Kategori & Frekuensi & $\%$ \\
\hline 1 & $\begin{array}{ll}41 & - \\
50 & \end{array}$ & $\begin{array}{l}\text { Sangat } \\
\text { Baik }\end{array}$ & 26 & $53,1 \%$ \\
\hline 2 & $\begin{array}{ll}31 & - \\
40 & \end{array}$ & Baik & 21 & $42,8 \%$ \\
\hline 3 & $\begin{array}{ll}21 & - \\
30 & \end{array}$ & Sedang & 2 & $4,1 \%$ \\
\hline 4 & $\begin{array}{ll}11 & - \\
20 & \\
\end{array}$ & Buruk & - & - \\
\hline 5 & $\begin{array}{ll}0 & - \\
10 & \end{array}$ & $\begin{array}{l}\text { Sangat } \\
\text { Buruk }\end{array}$ & - & - \\
\hline 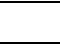 & 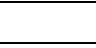 & Jumlah & 49 & $100 \%$ \\
\hline
\end{tabular}

Sumber : Data diolah, 2017

Dari 49 orang responden penelitian, pelatihan (X) pada Sekretariat DPRD Provinsi Lampung dalam kategori "sangat baik" ada 26 orang $(53,1 \%)$, yang menyatakan "baik" ada 21 orang $(42,8 \%)$, dan yang menyatakan "sedang" ada 2 orang atau $(4,1 \%)$, sedangkan yang menyatakan "buruk" dan "sangat buruk" tidak ada $(0 \%)$.

Tabel Distribusi Data Kinerja (Y) secara keseluruhan

\begin{tabular}{|c|c|c|c|c|}
\hline No & Skor & Kategori & Frekuensi & $\%$ \\
\hline 1 & $\begin{array}{ll}41 & - \\
50 & \end{array}$ & $\begin{array}{l}\text { Sangat } \\
\text { Baik }\end{array}$ & 22 & $44,9 \%$ \\
\hline 2 & $\begin{array}{ll}31 & - \\
40 & \end{array}$ & Baik & 24 & $49,0 \%$ \\
\hline 3 & $\begin{array}{ll}21 & - \\
30 & \\
\end{array}$ & Sedang & 3 & $6,1 \%$ \\
\hline 4 & $\begin{array}{ll}11 & - \\
20 & \end{array}$ & Buruk & - & - \\
\hline 5 & $0-10$ & $\begin{array}{l}\text { Sangat } \\
\text { Buruk }\end{array}$ & - & - \\
\hline & & Jumlah & 49 & $100 \%$ \\
\hline
\end{tabular}

Dari 49 orang responden penelitian, Kinerja (Y) pada Sekretariat DPRD Provinsi Lampung dalam kategori "sangat baik" ada 22 orang (44,9\%), yang menyatakan "baik" ada 24 orang (49\%), dan yang menyatakan "sedang" ada 3 orang $(6,1 \%)$. Sedangkan yang menyatakan "buruk" dan "sangat buruk" tidak ada $(0 \%)$.

Berdasarkan hasil jawaban responden diatas dapat dijelaskan bahwa secara umum budaya organisasi dan kinerja pada Sekretariat DPRD Provinsi Lampung dalam kondisi baik. Kecenderungan jawaban secara dominan menggambarkan kondisi yang baik ini tentunya bila semakin ditingkatkan akan mendorong kinerja pegawai yang tinggi pada Sekretariat DPRD Provinsi Lampung.

\section{Uji Hipotesis (t)}

Tabel Uji Hipotesis

Coefficients

\begin{tabular}{|c|c|c|c|c|c|}
\hline \multirow[t]{2}{*}{ Model } & \multicolumn{2}{|c|}{$\begin{array}{l}\text { Unstandardized } \\
\text { Coefficients }\end{array}$} & \multirow{2}{*}{$\begin{array}{c}\text { Stand } \\
\text { ardize } \\
\text { d } \\
\text { Coeffi } \\
\text { cients } \\
\text { Beta }\end{array}$} & \multirow[t]{2}{*}{$\mathrm{t}$} & \multirow[t]{2}{*}{ Sig. } \\
\hline & B & $\begin{array}{l}\text { Std. } \\
\text { Error }\end{array}$ & & & \\
\hline $\begin{array}{ll}\text { (Const } \\
\text { ant) }\end{array}$ & $-1,799$ & ,891 & & $-2,020$ & ,049 \\
\hline $\mathrm{X}$ & 1,043 & ,023 & 989 & 45,893 & ,000 \\
\hline
\end{tabular}

Berdasarkan hasil uji t didapat nilai $t_{\text {hitung }}=45,893$. Apabila dibandingkan dengan $\mathrm{t}_{\text {tabel }}(\mathrm{df}=\mathrm{n}-2)$ pada taraf signifikan yaitu 1,678, maka $t_{\text {hitung }}=45,893<\mathrm{t}_{\text {tabel }}=$ 1,678 sehingga dapat disimpulkan bahwa variabel Budaya Organisasi (X) berpengaruh terhadap Kinerja (Y). Berdasarkan kondisi tersebut, bentuk persamaan regresinya sebagai berikut:

$$
\begin{gathered}
Y=a+b X+e \\
Y=-1,799+1,043 X+e
\end{gathered}
$$


Dimana :

$\mathrm{Y} \quad=$ Kinerja

a $\quad=$ konstanta

$\mathrm{b} \quad=$ Koefisien Regresi $\mathrm{X}$

$\mathrm{X}=$ Budaya Organisasi

$\mathrm{e} \quad=$ error term (tingkat kesalahan)

Nilai koefisien budaya organisasi sebesar 1,043 menunjukkan apabila budaya organisasi meningkat sebesar 1 satuan maka kinerja juga akan meningkat sebesar 1,043 satuan.

\section{KESIMPULAN DAN SARAN}

\section{Kesimpulan}

Berdasarkan analisis data dan pembahasan pada bab sebelumnya, diperoleh kesimpulan sebagai berikut:

Hasil penelitian menunjukkan bahwa budaya organisasi (X) pada Sekretariat DPRD Provinsi Lampung dalam kategori baik. Untuk perhitungan koefisien determinasi variabel budaya organisasi pada tabel diatas diperoleh angka $\mathrm{R}^{2}$ ( $\mathrm{R}$ Square) sebesar 0,978 atau 97,8\%. Hal ini menunjukkan bahwa persentase sumbangan perubahan variabel independen budaya organisasi $(\mathrm{X})$ terhadap variabel dependen kinerja (Y) sebesar 97,8\% dan sisanya dipengaruhi faktor lain. Uji hipotesis parsial melalui uji $\mathrm{t}$ test diperoleh nilai $\mathrm{t}$ hitung budaya organisasi terhadap kinerja sebesar 45,893 dan $t_{\text {hitung }}=45,893>\mathrm{t}_{\text {tabel }} 1,678$. Persamaan regresi antara budaya organisasi dan kinerja pada Sekretariat DPRD Provinsi Lampung adalah sebesarY $=-1,799+1,043$ $\mathrm{X}+\mathrm{e}$, yang menunjukkan setiap kenaikan satu satuan dari variabel budaya organisasi akan diikuti oleh naiknya variabel kinerja pada Sekretariat DPRD Provinsi Lampung sebesar 1,043 satuan. Berdasarkan penelitian ini peneliti menyimpulkan bahwa budaya organisasi merupakan salah satu unsur penting dalam meningkatkan kinerja. Dengan membuat kegiatan positif bagi pegawai dan pimpinan dapat menimbulkan hubungan yang baik antar sesama pegawai maupun pegawai dengan pimpinan.

\section{Saran}

Adapun saran-saran yang dapat penulis sampaikan adalah sebagai berikut :

a. Hendaknya pimpinan dapat memberikan mendengarkan dan mempertimbangkan pendapat dari para pegawai nya, sehingga pegawai semangat dan termotivasi dalam mengerjakan tugas yang diberikan.

b. Untuk meningkatkan kinerja pegawai, hendaknya pimpinan harus memberikan pengarahan dan bimbingan kepada pegawai nya agar dapat lebih cermat dan teliti dalam mengerjakan tugas.

\section{DAFTAR PUSTAKA}

Arikunto, Suharsimi. 2002. Prosedur Penelitian Ed Revisi $V$. Jakarta: Rineka Cipta.

Ghozali, Imam. 2009. Aplikasi Analisis Multivariate dengan Program SPSS Ed Keempat. Semarang: UNDIP.

Laudon, Kenneth C. dan Laudon, Jane P. 2012. Sistem Informasi Manajemen, Mengelola Perusahaan Digital, Buku 1 Edisi 10. Jakarta: Salemba Empat.

Mangkunegara, AA. Prabu. 2009. Manajemen Sumber Daya Manusia Perusahaan, Cetakan ke sembilan. Bandung: PT. Remaja Rosdakarya.

Notoadmojo, $\quad$ Soekidjo. 2009. Pengembangan Sumber Daya Manusia, Cetakan keempat. Jakarta: Rineka Cipta. 
Rivai, Veithzal. dan Mulyadi, Deddy. 2012.

Kepemimpinan dan Perilaku

Organisasi, Edisi Ketiga. Jakarta:

PT. Raja Grafindo Persada.

Robbins, Stephen P. dan Judge, Timothy

A. 2008. Perilaku Organisasi, Buku

2. Jakarta: Salemba Empat.

Tintami, Lila., Pradhanawati, Ari., dan Susanto, Hari. 2012. "Pengaruh Budaya Organisasi Dan Gaya Kepemimpinan Transformasional Terhadap Kinerja Karyawan Melalui Disiplin Kerja Pada Karyawan Harian SKT Megawon II PT. Djarum Kudus". e-Journal, Vol. 2, No.1: 1-8.

Mathis, Robert. L \& Jackson. H. 2006. Manajemen Sumber Daya Manusia, Edisi 10. Jakarta: Salemba Empat

Sedarmayanti. 2011. Manajemen Sumber Daya Manusia dan Manajemen PNS, Cetakan Kelima. Bandung: PT. Refika Aditama.

Siagian, Sondang P. 2001. Manajemen Sumber Daya Manusi. Jakarta: Gunung Agung.

Handoko, T. Hani. 1999. Manajemen Edisi kedua. Yogyakarta: BPFE.

Irawan, .2002. Manajemen Personalia. Yogyakarta:BPFE. 